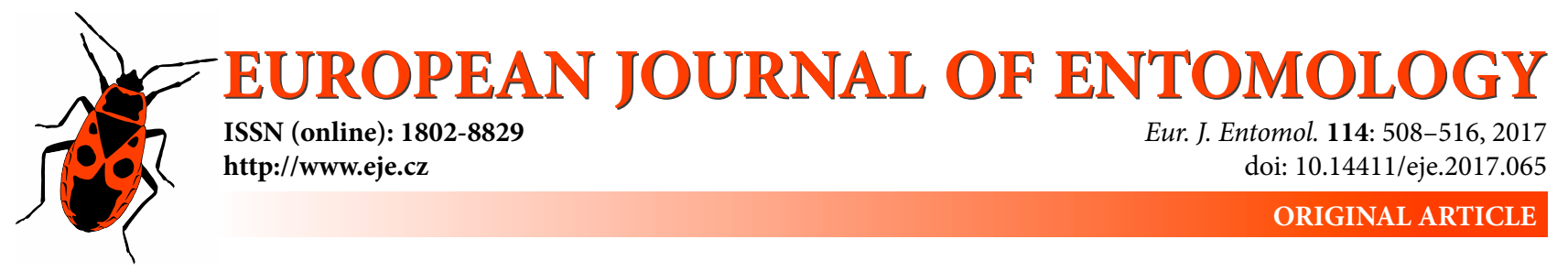

\title{
Comparison of gut morphology and distribution of trehalase activity in the gut of wood-feeding and fungus-growing termites (Isoptera: Termitidae)
}

\author{
NuJira TATUN, Chutamas SAWATNATHI, Suwakan TANSAY and Jatuporn TUNGJITWITAYAKUL
}

School of Science, University of Phayao, 19 Moo 2 Maeka subdistrict, 56000 Phayao, Thailand; e-mails: nujira.ta@up.ac.th, t_jatuporn@hotmail.com

Key words. Isoptera, Termitidae, gut, digestion, trehalase, cellulase, validamycin, evolution, termite

\begin{abstract}
Termites are important decomposer due to their ability to digest cellulose and their diverse feeding habits. Trehalase is an enzyme that hydrolyzes trehalose to glucose in insects and has an important biological role. Gut morphology of wood-feeding termites (Globitermes sulphureus, Termitinae; Microcerotermes crassus, Termitinae and Bulbitermes prabhae, Nasutitermitinae) and fungus-growing termites (Macrotermes annandalei, Macrotermitinae) that belong to the family Termitidae was determined in this study. Results indicate that wood-feeding termites have a similar gut morphology, which consists of a foregut, midgut and elongated hindgut, which is divided into four segments. More specifically the enlarged segment in the hindgut, called a paunch, is prominent in wood-feeding termites, whereas fungus-growing termites have a simpler tubular gut with a very small paunch. Trehalase activity was high in the midgut of wood-feeding termites (G. sulphureus, Mi. crassus and B. prabhae), but in the fungus-growing termite (Ma. annandalei) the highest level of activity was recorded in the hindgut. Cellulase activity (endo- $\beta-1,4-$ glucanase) was detected in all gut segments with very high levels in the hindguts of $B$. prabhae and Ma. annandalei. Differences in the distribution of trehalase and gut morphology correspond to the phylogenetic analyses of Termitidae, which indicate that Macrotermitinae is the sister group of Termitinae and Nasutitermitinae. In addition, validamycin suppressed trehalase activity in termites in vitro and in vivo, resulting in a high mortality in wood-feeding and fungus-growing termites, indicating that trehalase inhibitors could be useful tools for termite control.
\end{abstract}

\section{INTRODUCTION}

Termites are globally important as economic insect pests because they can digest cellulose. It is estimated that annual termite damage, control and repair costs exceed $\$ 20$ billion worldwide ( $\mathrm{Su}, 2002)$. However, termites have important roles in nutrient and carbon cycling in ecosystems (Ohkuma, 2003). Although there are many studies on termites, there is little information about the physiology of trehalose metabolism in termites even though it is the main haemolymph sugar in most insects (Becker et al., 1996).

Trehalose ( $\alpha$-D-glucopyranosyl- $\alpha$-D-glucopyranoside), a disaccharide in which two glucose molecules are linked by an $\alpha-1-1$-bond, is the most abundant carbohydrate in haemolymph and is used for energy production and macromolecular synthesis in insects. Trehalose must be converted into glucose before transport into cells because cell membranes are impermeable to this sugar. This conversion is achieved by the glycolytic enzyme trehalase ( $\alpha$-glucoside1-glucohydrolase, EC 3.2.1.28), which hydrolyses trehalose to yield two glucose monomeric units (Terra et al., 1996). Trehalase plays an important role in biological functions, such as homeostasis and development in many insects. Trehalase activity differs in the different developmental stages of insects (Shukla et al., 2014). For instance, enzymatic activity of trehalase and its gene expression are strongly correlated with the developmental profile of the red flour beetle, Tribolium castaneum, and the bamboo borer, Omphisa fuscidentalis (Tatun et al., 2008, Tatun et al., 2014a). More over trehalase is regarded as a promising target in the development of new techniques for controlling insect pests (Jin \& Zheng, 2009).

Termites are efficient decomposers of cellulose and exhibit high cellulolytic activity derived from both endogenous and symbiont cellulases. However, Tokuda et al. (2005) reports that the cellulase activities in a fungusgrowing termite, Odontotermes formosanus, are barely sufficient for survival on native cellulose. This is consistent with a report that wood-feeding termites (Termitidae family) exhibit a higher cellulase activity than fungus-growing termites ( $\mathrm{Li}$ et al., 2013). This is supported by a study of another fungus-growing termite, $O$. feae, in which the activity of trehalase is higher than that in the wood-feeding termite Coptotermes gestroi (Rhinotermitidae) (Tatun et al., 2014b). Thus, trehalase could be a candidate enzyme 
for the hydrolyzation of trehalose into glucose in fungal nodules and mycelia, which provides the energy required by fungus-growing termites. A study of the distribution of trehalase in the intestinal tract of the workers of $O$. feae revealed that the main sources of trehalase are the midgut and hindgut (Tatun et al., 2014b). Trehalase activity is also detected in salivary glands, fat body and generally throughout the body. In particular, there is relatively high enzyme activity in the luminal contents of the mid and hindguts compared with other tissues. It is not certain whether other higher termites, including termites with wood-feeding habits and other fungus-growing termites exhibit a similar pattern in trehalase activity to that reported in $O$. feae. Several other researches have also highlighted the importance of variations in trehalase expression in response to various stimuli such as environmental stressors and insecticides (Shukla et al., 2014), but there is no information on the association between trehalase activity and the evolution of termites. In this study we examined the morphology of the gut and determined the distribution of trehalase and cellulase activity in the gut of termites in the family Termitidae, the largest family, including three species of wood-feeding termites, Globitermes sulphureus (Termitinae), Microcerotermes crassus (Termitinae), and Bulbitermes prabhae (Nasutitermitinae), and a fungus-growing termite, Macrotermes annandalei (Macrotermitinae), with the aim of improving our understanding of the distribution of trehalase in termite guts and the differences in their gut morphology. The resulting data may reveal the relation between trehalase and the evolution of the digestive tract in termites, especially in the Termitidae.

Validamycin, a trehalose analog strongly inhibits the activity of trehalase in various organisms, including isopteran insects. It is known to have an insecticidal effect by inhibiting trehalase activity in the fungus-growing termite O. feae (Tatun et al., 2014b). Trehalase inhibition in termites has recently become important in the development trehalase inhibitors for controlling termites, however, further studies on the effects of validamycin on other species of termites are needed. Hence, the inhibitory and lethal effects of validamycin on termites were examined in the present study. The resulting data will be useful for understanding the hydrolysis of trehalose as an energy source in different species of termites with different feeding habits and may provide useful information for the development of new termite control strategies.

\section{MATERIALS AND METHODS}

\section{Insects}

Individuals of G. sulphureus, Mi. crassus, B. prabhae and Ma. annandalei were collected from the University of Phayao, Thailand. The morphological characteristics of the soldier caste were used for species identification with the help of The Forest Research and Development Bureau, Royal Forest Department, Ministry of Natural Resources and Environment, Thailand.

\section{Photography}

Worker termites from each species were dissected with fine forceps under a stereomicroscope (Olympus Corporation, Tokyo,
Japan) and photographs of their intestinal tracts taken with a digital camera. These photographs were adjusted for brightness and contrast using Adobe Photoshop CS3 (Adobe Systems Incorporated, San Jose, CA, USA).

\section{Preparation of termite trehalase from intestinal tract}

After collecting termites from three different colonies, they were dissected immediately under a stereomicroscope and the whole guts isolated from workers were washed in $20 \mathrm{mM}$ sodium phosphate buffer ( $\mathrm{PB}, \mathrm{pH}$ 6.0) and then divided into three sections: foregut, midgut and hindgut, using a pair of dissection forceps. The foreguts, midguts and hindguts isolated from workers $(n=200)$ were placed on a cavity slide containing a $150 \mu \mathrm{l}$ drop of $20 \mathrm{mM}$ PB. Each section of gut was torn using dissecting needles to liberate their contents. The solution remaining on a slide were collected into a $1.5 \mathrm{ml}$ microtube, followed by homogenization using a plastic pestle and three freeze-thaw cycles. The gut tissues were transferred using fine forceps to another microtube containing $500 \mu \mathrm{l}$ of $20 \mathrm{mM}$ PB (pH 6.0). These tubes were shaken thoroughly in a vortex mixer for $5 \mathrm{~s}$ and subjected to centrifugation at $3,000 \times \mathrm{g}$ for $10 \mathrm{~min}$ at $4^{\circ} \mathrm{C}$. The supernatant was discarded and the resulting tissue pellet was washed twice with $20 \mathrm{mM}$ PB $(1,000 \mu \mathrm{l})$. The pellets were then homogenized in 500 $\mu 1$ of $20 \mathrm{mM}$ PB using a plastic pestle followed by three freezethaw cycles. Homogenized samples were filtered through a small pad of sterile cotton wool to remove debris and the filtrates used as the homogenate in the trehalase activity assay. Determination of protein content in each sample was carried out using the protein dye-binding method with bovine serum albumin (BSA) as the standard (Bio-Rad, Hercules, CA, USA) prior to the assessment of enzyme activity. The Bradford dye reagent (1 part) was diluted with deionized water (4 parts) and filtered through filter paper to remove any particules. The linear concentration range of BSA was 1.25 to $10 \mu \mathrm{g} / \mathrm{ml}$. Each standard protein and sample $(20 \mu \mathrm{l})$ was added to a $1.5 \mathrm{ml}$ microtube containing $1.0 \mathrm{ml}$ of diluted dye. The tube was shaken on a vortex mixer and incubated at room temperature for $5 \mathrm{~min}$. The absorbance at $595 \mathrm{~nm}$ was measured using a UV-Vis spectrophotometer (BioMate ${ }^{\mathrm{TM}} 3 \mathrm{~S}$, Thermo Scientific, Waltham, MA, USA). Protein concentration in each sample was assayed in triplicate. The termites used for the replicates were collected from three different colonies.

\section{Preparation of termite trehalase from whole workers and soldiers}

Whole workers and soldiers were collected from three different colonies and used immediately to prepare the homogenates for assessing trehalase activity in worker and soldier castes separately. Each sample $(n=3)$ was homogenized using a plastic pestle in $500 \mu \mathrm{l}$ of $20 \mathrm{mM}$ PB (pH 6.0). After three freeze-thaw cycles to further break the cell membranes, the homogenized samples were filtered through a small pad of sterile cotton wool. The filtrates were centrifuged at $10,000 \times \mathrm{g}$ for $10 \mathrm{~min}$ at $4^{\circ} \mathrm{C}$ and the supernatant was kept at $-20^{\circ} \mathrm{C}$ until required.

\section{Trehalase activity assay}

Trehalase activity was measured by determining the rate of glucose production resulting from trehalose hydrolysis. The homogenate was $(50 \mu \mathrm{l})$ added to the $1.5 \mathrm{ml}$ microtube containing $60 \mu \mathrm{l}$ of $40 \mathrm{mM}$ trehalose (Sigma, St. Louise, MO, USA) and the final volume adjusted to $250 \mu \mathrm{l}$ by addition of $20 \mathrm{mM}$ PB. Following incubation at $37^{\circ} \mathrm{C}$ for $60 \mathrm{~min}$, the reaction was terminated by immersing the tube in a boiling water bath for $5 \mathrm{~min}$. After cooling, the insoluble material was separated by centrifugation at $12,000 \times$ $\mathrm{g}$ for $10 \mathrm{~min}$ at $4^{\circ} \mathrm{C}$, and the supernatant was collected and used to determine the concentration of glucose. Measurement of the amount of glucose was done using a spectrophotometer coupled 
enzyme assay using hexokinase and glucose-6-phosphate dehydrogenase (Roche Diagnostics GmbH, Mannheim, Germany) (Bergmeyer et al., 1974). The reaction mixture was prepared in a $1.5 \mathrm{ml}$ microtube, which contained 50 units of hexokinase, 100 units of glucose-6-phosphate dehydrogenase, $2 \mathrm{mM}$ NADP and $2.8 \mathrm{mM}$ ATP (Roche Diagnostics GmbH, Mannheim, Germany). The sample $(100 \mu \mathrm{l})$ was added to the reaction mixture, incubated at $25^{\circ} \mathrm{C}$ for $60 \mathrm{~min}$ and transferred to a $1.5 \mathrm{ml}$ plastic cuvette. The amount of NADPH generated from the reaction is stoichiometric with the amount of glucose. The NADPH was measured using the increase in absorbance at $340 \mathrm{~nm}$ recorded on a UV-Vis spectrophotometer (BioMate ${ }^{\mathrm{TM}} 3 \mathrm{~S}$, Thermo Scientific, Waltham, MA, USA). Trehalase activity was determined using a glucose standard curve (Sigma, St. Louise, MO, USA), and the enzymatic activity was expressed in nmol of glucose $/ \mu \mathrm{g}$ of protein $/ \mathrm{min}$. Trehalase activity was presented as nmol of glucose $/ \mathrm{min} / \mu \mathrm{g}$ of protein. This experiment was replicated three times.

\section{Assay of cellulase activity}

The guts of G. sulphureus, Mi. crassus, Ma. annandalei and B. prabhae workers $(\mathrm{n}=60)$ were divided into foregut, midgut and hindgut. Each gut section was homogenized in $500 \mu \mathrm{l}$ of ice-cold buffer ( $100 \mathrm{mM}$ sodium acetate buffer, $\mathrm{pH}$ 5.6). The homogenized samples were subjected to centrifugation at $10,000 \times \mathrm{g}$ for $15 \mathrm{~min}$ at $4{ }^{\circ} \mathrm{C}$, and the supernatant kept for assessing cellulase activity. Activity (endo- $\beta-1,4$-glucanase) was measured using $1 \%$ sodium carboxymethyl cellulose (Sigma, St. Louis, MO, USA) as a substrate. The reaction mixture consisted of $50 \mu \mathrm{l}$ of homogenate, $120 \mu \mathrm{l}$ of sodium acetate buffer and $120 \mu \mathrm{l}$ of the substrate. After $60 \mathrm{~min}$ at $37^{\circ} \mathrm{C}$ of incubation, the reaction was terminated by immersing the tube in a boiling water bath for $5 \mathrm{~min}$ and cooled in an ice bath. The generated reducing sugar was measured following the procedure described by Li et al. (2013). Concentration of protein in each sample was determined spectrophotometrically at $595 \mathrm{~nm}$ using the protein dye-binding method as described above (Bio-Rad, Hercules, CA, USA). Enzyme activity was presented as the amount of reducing sugar generated per $\mu \mathrm{g}$ of protein per $\min$.

\section{Validamycin treatment}

First, homogenates of four species of termites (G. sulphureus, Mi. crassus, B. prabhae, and Ma. annandalei) were mixed with validamycin $(30 \mathrm{ng} / \mu \mathrm{l})$ prior to the addition of trehalose in order to determine the inhibitory activity of validamycin in vitro. Next, the inhibitory activity of validamycin against trehalase in termites was examined in vivo by soaking filter paper with validamycin and feeding it to worker termites of G. Sulphureus and Ma. an$n a n d a l e i$, species that are wood-feeding and fungus-growing termites, respectively. Changes in trehalase activity were examined after ingestion of filter paper treated validamycin. Termites (10 workers plus 2 soldiers) were reared in a Petri dish containing filter paper treated with $300 \mathrm{ng} / \mathrm{ml}$ of validamycin $(1 \mathrm{ml})$. In the control experiment, the filter paper was treated with distilled water. The Petri dishes were stored in a plastic box containing wet paper towels and stored in a dark cabinet. Termite samples were collected daily for assessing trehalase activity. In addition, the percentage mortality of G. sulphureus and Ma. annandalei after ingestion of filter paper soaked with various concentrations of validamycin $(75-600 \mathrm{ng} / \mathrm{ml})$ was also recorded at $3 \mathrm{~d}$ posttreatment using the same method as described earlier. This experiment was replicated three times.
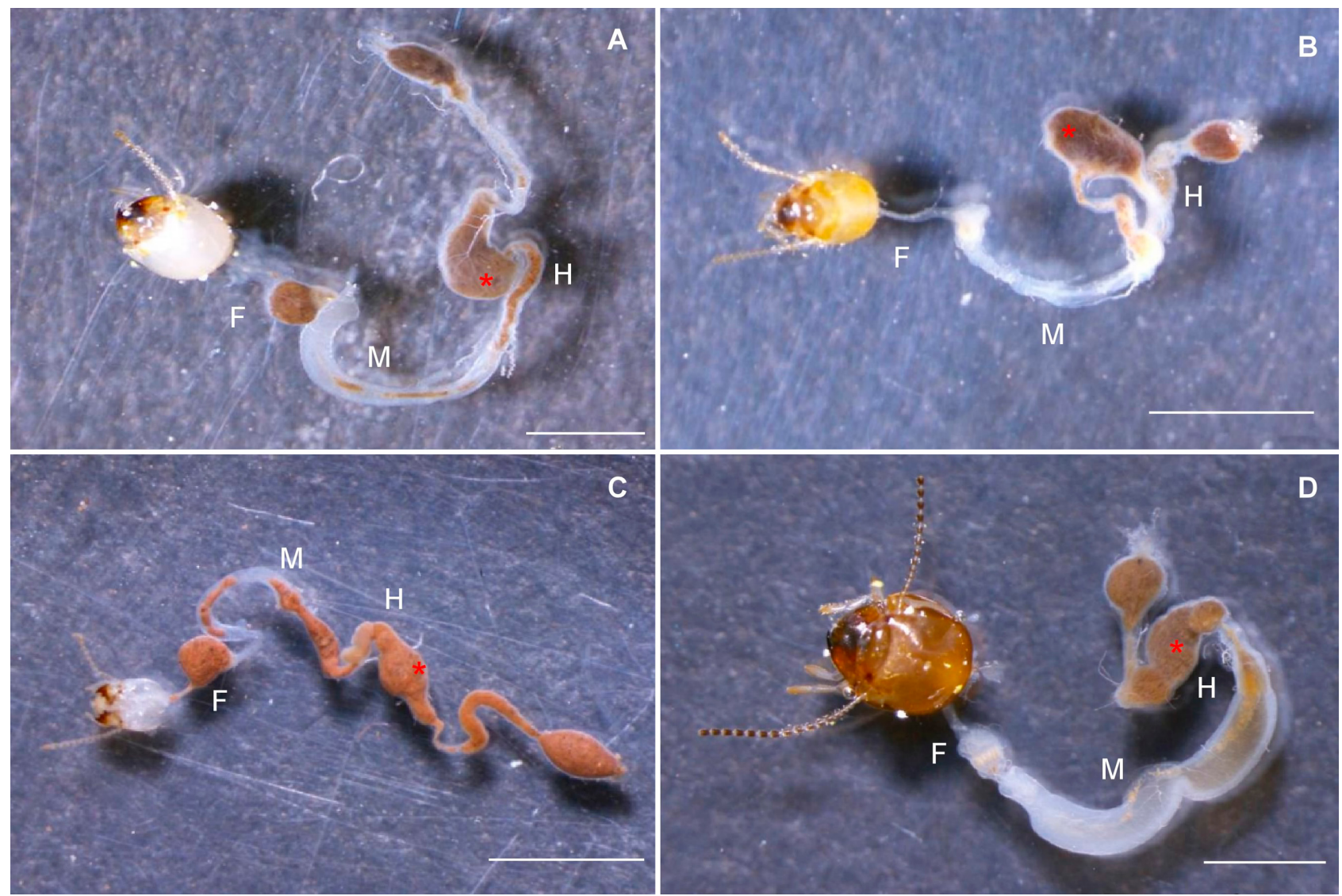

Fig. 1. Photographs of the intestinal tracts of G. sulphureus (A), Mi. crassus (B), B. prabhae (C) and Ma. annandalei (D). Each photograph includes the head on the far left and the intestinal tract is divided into foregut $(F)$, midgut $(M)$ and hindgut $(H)$. Scale bar $=2 \mathrm{~mm}$. The paunch in the hindgut is indicated by a red asterisk. 

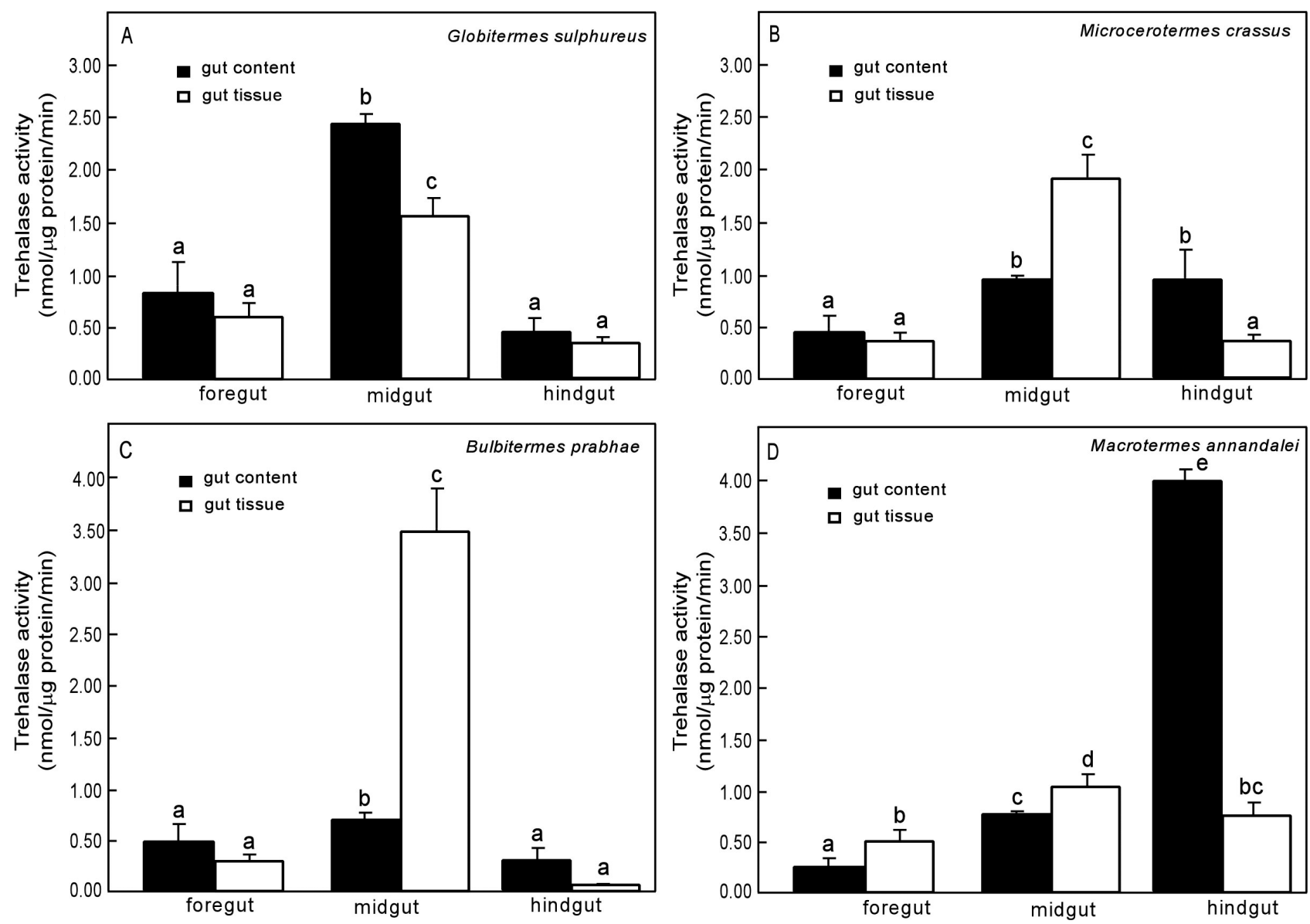

Fig. 2. Distribution of trehalase activity in the three parts of the intestinal tract of workers of G. sulphureus (A), Mi. crassus (B), B. prabhae (C) and Ma. annandalei (D). The luminal contents of the foregut, midgut and hindgut (solid bar) were separated from their tissues (open

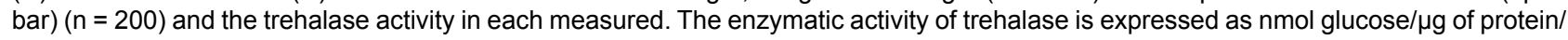
min. Error bars indicate SD. The values labelled with different letters are significantly different $(P<0.05)$.

\section{Statistical analysis}

A one-way-ANOVA, followed by the least significant difference (LSD) multiple range test, was used for statistical analyses (SPSS version 11.5). Significant differences between the enzymatic activity in soldier and worker castes and trehalase activity in termites that had ingested validamycin and the control were calculated using an independent-sample t-test. The significance level was set at $0.05(P<0.05)$.

\section{RESULTS}

\section{Gut morphology}

The differences in gut morphology of the four species that feed on different foods are shown in Fig. 1. The termite gut generally consists of a foregut, midgut, and hindgut. The gut morphologies of G. sulphureus and Mi. crassus are similar (Fig. 1A and B), consisting of a foregut, tubular midgut and long hindgut with modifications including a narrow tube at the junction with the midgut, which is the entrance to the paunch (enlarged sac at the beginning of the hindgut), followed by the colon and rectum. The anterior part of the paunch has a spherical shape and the posterior end is cone-shaped. Interestingly, B. prabhae has the longest gut of the species examined, which is approximately 10 times the length of the head part (Fig. 1C). However, the paunch in B. prabhae is not as prominent as in G. sul- phureus and Mi. crassus. The simple gut of Ma. annandalei lacks an elongated and highly differentiated hindgut typical of higher termites (Fig. 1D). The hindgut of Ma. annandalei has a tubular shape, similar to the midgut and the paunch is not prominent. More specifically, the length of the paunch was measured and the ratio of the paunch length to head length was calculated. This revealed that the paunch length to head length ratio for G. sulphureus, Mi. crassus, B. prabhae and Ma. annandalei are 1.9, 0.68, 1.0 and 0.24 , respectively.

\section{Distribution of trehalase activity in the digestive tract}

Trehalase was extracted from gut tissue and gut luminal contents, and its activity in each case was determined (Fig. 2). In the wood-feeding termite, G. sulphureus, Mi. crassus and $B$. prabhae trehalase activity was detected in all three parts of the gut (Fig. 2A-C). Low levels of enzyme activity were detected in both the luminal contents and tissues of the fore and hindguts. In contrast, trehalase activities in the midguts of all three species were the highest recorded (Fig. 2A-C). Trehalase activity in the contents of the midgut of $G$. sulphureus was higher than that in midgut tissues, whereas trehalase activity in midgut tissues was higher than in the contents of the midguts in $M i$. 


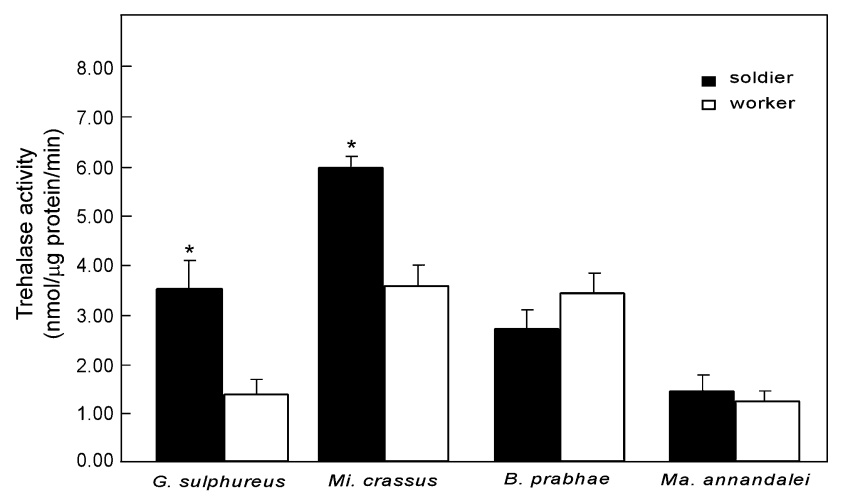

Fig. 3. Trehalase activity in the soldier and worker castes of $G$. sulphureus, Mi. crassus, B. prabhae and Ma. annandalei. Whole animals $(n=3)$ were used in the preparation of the homogenate for measuring trehalase activity. Trehalase activity is expressed as in Fig. 2. The asterisks above the bars indicate significant difference between soldier and worker castes within species $(P<0.05)$.

crassus and B. prabhae. Interestingly, trehalase activity in the fungus-growing termite, Ma. annandalei, was at a low level in the foregut, higher in the midgut and highest in the hindgut (Fig. 2D). More specifically, the highest activity $(3.8 \mathrm{nmol} / \mu \mathrm{g}$ protein $/ \mathrm{min})$ was recorded in the contents of the hindgut in Ma. annandalei, which is five-fold greater than that recorded in the tissues of the hindgut $(0.75 \mathrm{nmol} /$ $\mu \mathrm{g}$ protein/min).

\section{Comparison of trehalase activity in soldier and worker castes}

A higher trehalase activity was recorded in the soldier castes of G. sulphureus and Mi. crassus (3.5 and $6.1 \mathrm{nmol} /$ $\mu \mathrm{g}$ protein $/ \mathrm{min}$, respectively) than the worker castes $(1.3$ and $3.6 \mathrm{nmol} / \mu \mathrm{g}$ protein $/ \mathrm{min}$, respectively) (Fig. 3). In contrast, there were no differences in the trehalase activity recorded in the soldier and worker castes in Ma. annandalei and B. prabhae.

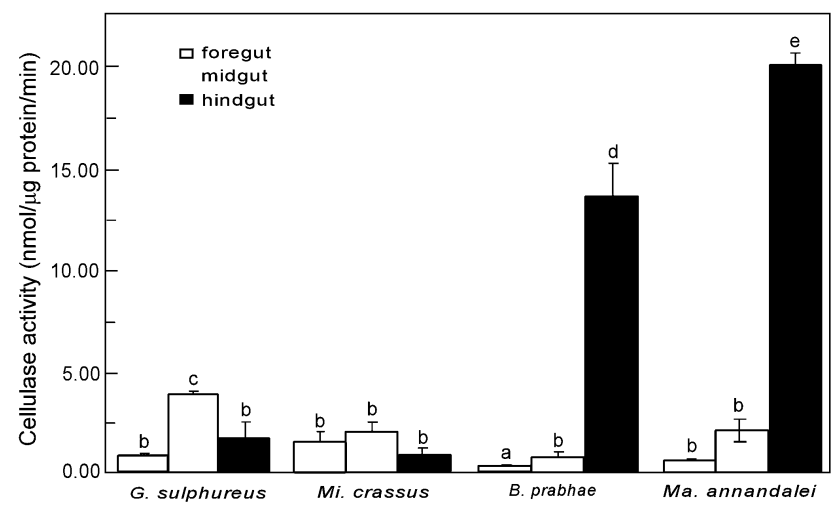

Fig. 4. Distribution of cellulase (endo- $\beta-1,4-$ glucanase) activity in three different parts of the intestinal tract of workers of $G$. sulphureus (A), Mi. crassus (B), B. prabhae (C) and Ma. annandalei (D). The homogenate was prepared from foregut, midgut or hindgut of worker termites $(n=60)$. The enzymatic activity of cellulase is expressed as nmol of reducing sugar/ $\mathrm{\mu g}$ of protein/min. Error bars indicate SD. The values labelled with different letters are significantly different $(P<0.05)$.

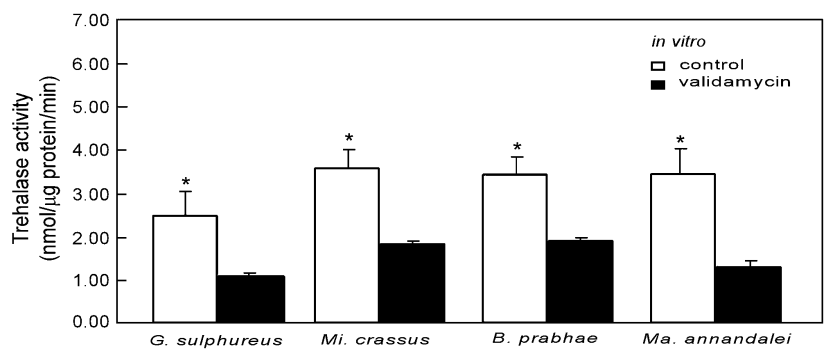

Fig. 5. Changes in trehalase activity after treatment in vitro with validamycin. The homogenate from worker termites of $G$. sulphureus, Mi. crassus, B. prabhae and Ma. annandalei was incubated with validamycin (complete bars) and $20 \mathrm{mM}$ phosphate buffer in the control (open bars).

\section{Distribution of cellulase activity in the digestive tract}

Homogenates of the fore, mid and hind guts of four species of termites were prepared and used to determine cellulase (endo- $\beta$-1,4-glucanase) activity (Fig. 4). The activity of cellulase in the foreguts of all the termites tested was low. In G. sulphureus, the highest activity was recorded in the midgut, with low levels recorded in the fore and hind guts. Cellulase activities recorded in the fore, mid and hind guts in Mi. crassus were similar and low. Interestingly, the cellulase activity recorded in the hindguts was higher than in the fore and mid guts in B. prabhae and Ma. annandalei.

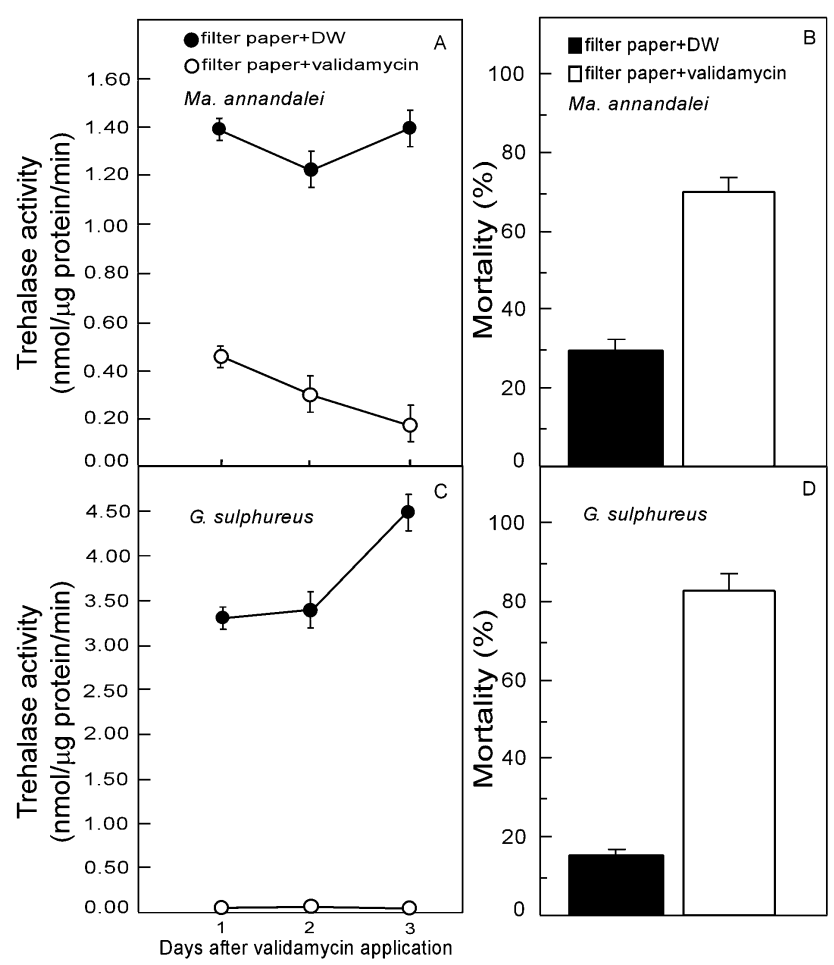

Fig. 6. Trehalase activity in whole body homogenate of worker termites $(n=3)$ of $G$. sulphureus and Ma. annandalei fed on filter paper soaked in validamycin (open circles) and sterilized distilled water (close circles) for 3 days (A, C). Trehalase is expressed as in Fig. 2. Error bars indicate SD. The values labelled with different letters are significantly different $(P<0.05)$. Percentage mortality of Ma. annandalei (B) and G. sulphureus (D) recorded on day 3 post-treatment. 


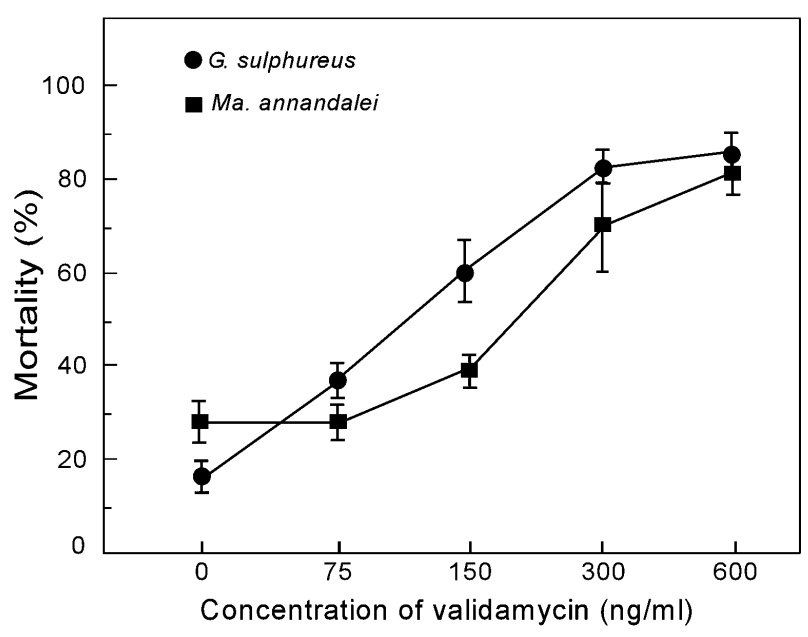

Fig. 7. Percentage mortality of worker termites of G. sulphureus and $M a$. annandalei 3 days after feeding on filter paper soaked in various concentrations of validamycin $(75-600 \mathrm{ng} / \mathrm{ml})$.

\section{Effect of validamycin on termite trehalase activity in vitro and in vivo}

Validamycin suppressed trehalase activity in vitro, with the activity decreasing to approximately $50 \%$ of that recorded in the control (Fig. 5). After ingestion of validamycin-treated filter paper, trehalase activity in $M a$. annandalei decreased markedly $24 \mathrm{~h}$ post-treatment and thereafter (Fig. 6A). Trehalase activity in G. sulphureus decreased to a very low level $24 \mathrm{~h}$ post-treatment and remained low until the end of experiment. Moreover, at $3 \mathrm{~d}$ post-treatment, many G. sulphureus and Ma. annandalei workers fed validamycin-treated filter paper had died $(80 \%$ and $70 \%$ mortality, respectively), whereas corresponding values for the control termites were only $18 \%$ and $30 \%$, respectively (Fig. 6B and D). In addition, $3 \mathrm{~d}$ post-treatment, the percentage mortality recorded for G. sulphureus and Ma. annandalei was concentration dependent (Fig.7). The percentage mortality of termites fed on filter paper soaked with distilled water was low (18\% and 30\%, respectively) and considerably less than that of the the termites fed on filter paper soaked with validamycin, for which the highest percentage mortality was recorded at a concentration of $600 \mathrm{ng} / \mathrm{ml}$ validamycin.

\section{DISCUSSION}

The guts of termites are very complex structures. Those in the basal families are similar to cockroaches, but more derived families have highly modified guts in which the hindguts have a structure that indicates a role in fermentation (Bignell et al., 2011). In the present study, all the termites studied were members of the family Termitidae and belonged to the subfamilies Termitinae, Nasutitermitinae and Macrotermitinae. The greatest variation in gut morphology is found in this family. Hindgut flagellates have been lost, and this appears to have accelerated the evolution of physiological and anatomical innovations (Bignell et al., 2011). The gut morphologies of the wood-feeding termites, G. sulphureus, Mi. crassus and B. prabhae, are similar and consist of a fore, mid and hindgut, with the lat- ter composed of an ileum (P1), enteric valve (P2), paunch (P3), colon (P4) and rectum (P5), as described in Noirot (2001). However, the length of gut of B. prabhae, a woodfeeding termite, is longer (approximately 10 times its head part length) than those of G. sulphureus and Mi. crassus. A possible reason for this difference in gut morphology is that they belong to a different subfamily (Nasutitermitinae and Termitinae, respectively) even though they share wood-feeding habits (Noirot, 2001). Similarly, other higher termites, such as wood-feeding and soil-feeding termites (Nasutitermitinae and Termitinae) are reported to have longer intestinal tracts and a more compartmentalized hindgut (Brune, 2014). Interestingly, the gut morphology in Ma. annandalei is a simple tube, with no enlarged region in the anterior hindgut. The general arrangement of the gut in $M a$. annandalei is similar to that in other members of the subfamily Macrotermitinae, including Macrotermes subhyalinus Rambur (Anklin-Mühlemann et al., 1995) and $O$. feae (Tatun et al., 2014b). The structure of the gut in the Macrotermitinae is very uniform and similar to the primitive condition in lower termites, in lacking a mixed segment and having a relatively short hindgut (Bignell, 1994). Moreover, the guts of lower termites and fungus growing termites (Macrotermitinae) are similar not only in terms of their morphology but also in physicochemical conditions (Brune, 2014). It is not known why fungus-growing termites are physiologically advanced but have a gut structure more similar to those of lower termites (Bignell, 1994). Based on phylogenetic studies, the digestive system of termites has undergone significant changes during the evolution of Termitidae, which is widely accepted as one of the most recently evolved lineages of termites. This indicates that these changes have been accompanied by greater modifications in the morphology of the guts of the Termitidae than in those of other termites (Bignell, 1994).

The midgut is the primary source of trehalase in many insects (Robsinski et al., 1979; Hirayama et al., 2007; Tatun et al., 2014b). The present study revealed similar results, with the highest trehalase activities recorded in the midguts of G. sulphureus, Mi. crassus and B. prabhae. The high trehalase activity in the midgut must considered in terms of the activity recorded in the lumen of the midgut and in the haemocoel around the midgut (Mitsumasu et al., 2005; Tatun et al., 2008). The latter may serve to supply glucose to the gut cells for their basic energy requirements and to other tissues to be used in reproduction and colony defence (soldier caste). The role(s) of the trehalase in the lumen of the gut remains unclear because the diets of these insects contain very little trehalose. However, this is not the case for the diets of fungus-growing termites that feed on fungi they cultivate in their nests. Interestingly, $\mathrm{Ma}$ annandalei is an exception with the highest activity recorded in its hindgut. Fungal mycelia and nodules are trehaloserich, which may account for why there is a higher level of trehalase activity in fungus-growing than wood-feeding termites. It is also interesting that there is higher trehalase activity in the contents of the hindgut than in the tissues in the hindgut. There are no reports of cells that secret diges- 
tive enzymes in the hindgut, which is regarded as the main absorption area in the gut for hydrolytes and water. Thus, the role of the hindgut may be restricted to absorption (Terra et al., 1996). However, the hindgut in termites contains diverse microbial symbionts at a density of $10^{6}-10^{8}$ per $\mu l$ (Hongoh et al., 2006). Several species of fungi are reported to have two different classes of trehalase, known as neutral and acid trehalases, which hydrolyze cytosolic trehalose and exogenous trehalose, respectively (Jorge et al., 1997). In addition, transcriptome analysis of Termitomyces albuminosus, which have a symbiotic relationship with the fungus-growing termite, O.formosanus, revealed the presence of many genes encoding glucoside hydrolases including trehalase (Yang et al., 2012). Thus the high trehalase activity in the hindgut of the fungus-growing termite (Ma. annandalei) may be from symbionts including fungi. However, further studies are needed to determine the origin of the trehalase in the lumen of the hindgut of this fungus-growing termite, especially the contribution of bacterial symbionts. The trehalase activity in the tissues of the midgut in B. prabhae is seven-fold higher than that in the contents of the midgut. The patterns in the distribution of trehalase in the guts of Mi. crassus and G. sulphureus differ from that recorded for B. prabhae even though all these termites feed on wood, but belong to different subfamilies, Termitinae and Nasutitermitinae, respectively. It is reported that termites feed on wood at different stages of decay and on other types of food, including lichens, humus and fungus nodules (Bignell et al., 2011). Feeding behaviour is a good indicator of their lifestyle and ecology (Eggleton \& Tayasu, 2001). Donovan et al. (2001) classify termite feeding groups according to the contents and functional morphology of their guts as follow. Group I includes wood feeders with relatively simple guts including all the lower termites. Group II, higher termites with more complex guts that feed on dead wood, epiphytes or leaf litter. Group III, termites that have complex guts and feed on organic-rich soil (humus layers) containing detectable amounts of plant material. Group IV, termites that have highly complex guts and feed on soil that contains only small amounts of plant material. Specifically, the termites belong to the subfamily Macrotermitinae are classified into group $\mathrm{II}_{\mathrm{f}}$ by Inward et al. (2007) because these termites share similar characteristics with those in this group, but have a simple gut and the ability to cultivate the symbiotic fungus Termitomyces in their nest. In the present study, three species of termites $(G$. sulphureus, Mi. crassus and B. prabhae) were classified as belonging in group 2 and $M a$. annandalei belonging in group $\mathrm{II}_{\mathrm{f}}$. The differences in the patterns in the distributions of trehalase activity in the guts of termites, therefore, could be associated with their feeding habits. Analysis of trehalase activity in G. sulphureus and Mi. crassus revealed that the activity in the soldier caste is higher than in the worker caste. It is reported that trehalase activity is caste specific in the fungus-growing termite, O. feae (Tatun et al., $2014 b$ ) and that this may be due to the amount of energy needed by soldiers for colony defence. However, there are differences in the composition of the material ingested not only by different species but also by the different castes, which might affect enzyme activity (Brune, 2014).

Cellulase (endo- $\beta-1,4$-glucanase) activity in wood-feeding termites is restricted to the midgut (Tokuda \& Watanabe, 2007). Our results for G. sulphureus are consistent with the observations of Tokuda \& Watanabe (2007), with the activity of endo- $\beta$-1,4-glucanase highest in the midgut. However, there was no difference in the cellulase activity in the three gut segments in Mi. crassus (Fig. 4). Whereas, the highest endo- $\beta-1,4$-glucanase activity in $B$. prabhae, a member of the subfamily Nasutitermitinae, was recorded in its hindgut. Cellulolytic systems in the Termitinae differ from those in the Nasutitermitinae (Slaytor, 2000). Interestingly, the fungus-growing termite, Ma. annandalei, had a pattern of endo- $\beta$-1,4-glucanase activity similar to that recorded in B. prabhae. An extraordinarily high level of endo- $\beta$-1,4-glucanase activity was recorded in the hindgut in Ma. annandalei in this study. Tokuda et al. (2004) previously report that the fungus-growing termite $O$. formosanus has a relatively higher endo- $\beta$-1,4-glucanase activity in its mid and hind guts rather than in its foregut. There are two cellulases in the conidiophores of the Termitomyces (basidiomycete fungus) cultivated by the higher fungus-growing termites (Macrotermes michaelseni and Macrotermes natalensis) and studies on their biochemical properties reveal that these cellulases are very active and highly active, respectively, in the metabolism of soluble and insoluble celluloses (Abo-Khatwa, 1989; Osore \& Okech, 1983). Termites consume fungal nodules rich in glucose and protein, including fungal cellulase. Therefore, fungal cellulase may be the source of the extraordinary high cellulase levels in Ma. annandalei. These results are also in agreement with studies indicating that symbiotic bacteria are involved in cellulolytic digestion in Nasutitermes takasagoensis Shiraki (Tokuda et al., 2005). Moreover, the presence of cellulolytic bacteria in the hindgut paunch of Nasutitermes spp. was revealed by a metagenomic analyses of the contents of the paunch, which identified many genes encoding glycoside hydrolases that are relevant to the degradation of cellulose (Brune, 2014). During the evolution of the Termitidae, cellulase expression shifted from the salivary glands to the midgut (Lo et al., 2012), but different species of termites differ in their cellulase activities. Based on the distribution of endo- $\beta$-1,4-glucanase in the guts of the four species of termites studied, it is suggested that B. prabhae (Nasutitermitinae) is more similar to $M a$. annandalei (Macrotermitinae) than to the other two woodfeeding termites (G. sulphureus and Mi. crassus; Termitinae). However, distribution of cellulase activity in the fungus-growing termites (Macrotermitinae subfamily) is more complicated, partly due to variations in the dependence of the different species of termites on their symbiotic fungi as a source of carbon (Hyodo et al., 2003). Li et al. (2013) note that the differentiation in the feeding habits of higher termites, flagellate-free termites, are associated with the distribution of cellulase in each gut segment rather than variations in the level of cellulase activity. Distribution of cellulase activity in the guts of higher termites is more 
variable. The reason for this is very unclear, but the major reason could have been an ecological event that affected cellulolytic systems during the evolution of termites (Ni $\&$ Tokuda, 2013). Hence, there are no clear conclusions on how fungus-growing higher termites digest cellulose. The present study revealed that gut morphology and the distributions of both trehalase and cellulase corresponded to the phylogenetic analyses of termites in the Termitidae, indicating that Macrotermitinae is the sister group of the Termitinae and Nasutitermitinae. In addition to cellulase, trehalase may be another enzyme the distribution along the gut of which has changed as gut morphology, digestive physiology and feeding behaviour has changed during the evolution of termites, because trehalase has important roles in both the digestion of food (trehalose in diets) and metabolism of sugar in haemolymph during growth, metamorphosis and moulting (Becker et al., 1996). Thus the distribution of trehalase in the guts of other termites could provide information that may help explain the evolution of termites, especially their digestive system.

Validamycin compounds inhibit the activity of termite trehalase (termite species not specified) in vitro (Jin \& Zheng, 2009). Validamycin inhibits trehalase activity in the fungus-growing termite $O$. feae (Tatun et al., 2014b). The present study revealed that validamycin compounds also inhibit trehalase activity in the wood-feeding termite $G$. sulphureus and the fungus-growing termite Ma. annandalei. Trehalase activity in both termites decreased markedly $1 \mathrm{~d}$ after treatment. The percentage mortality was concentration dependent and the high percentage mortality recorded indicates that validamycin could be used as an insecticide for controlling both wood-feeding and fungusgrowing termites, as it prevents the hydrolysis of trehalose, leading to a lack of glucose (Wegener et al., 2003). Validamycin is absorbed through the gut membrane into the haemocoel and may be absorbed into other tissues (Tatun et al., 2014b). Validamycin is a valuable tool for studying the role of trehalase in termites and for termite control. However additional experiments are needed to examine its other effects on termites and also the effect of validamycin on non-target organisms.

ACKNOWLEDGEMENTS. We would like to thank K. Charoenkrung of The Forest Research and Development Bureau, Royal Forest Department, Thailand for help with determining the identification of the termites. We are grateful to T. Suppasat, University of Phayao for collecting the termites. This study was supported by a grant from National Research Council of Thailand (RD59007) awarded to N.T.

DECLARATION OF INTEREST. The authors report no conflicts of interest.

\section{REFERENCES}

Aво-Kнатwa A.N. 1989: Termitomyces: A new source of potent cellulases. - J. King Abdulaziz Univ. (Sci.) 1: 51-59.

Anklin-Mühlemann R., Bignell D.E., Veivers P.C., Leuthold R.H. \& SLAYTOR M. 1995: Morphological, microbiological and biochemical studies of the gut flora in the fungus-growing termite Macrotermes subhyalinus. - J. Insect Physiol. 41: 929-940.

Becker A., Schlöder P., Steele J.E. \& Wegener G. 1996: The regulation of trehalose metabolism in insects. - Experientia 52: 433-439.

Bergmeyer H.U., Bernt E., Schmidt F. \& Stork H. 1974: D-glucose determination and glucose-6-phosphate dehydrogenase. In Bergmeyer H.U. (ed.): Methods of Enzymatic Analysis. Vol. 3. Academic Press, New York, pp. 1196-1201.

BigNell D.E. 1994: Soil-feeding and gut morphology in higher termites. In Hunt J.H. \& Nalepa C.A. (ed.): Nourishment and Evolution in Insect Societies. Westview Press, Boulder, CO, pp. 131-158.

Bignell D.E., Roisin Y. \& Lo N. (eds) 2011: Biology of Termites: a Modern Synthesis. Springer, Dordrecht, 576 pp.

Brune A. 2014: Symbiotic digestion of lignocellulose in termite guts. - Nat. Rev. Microbiol. 12: 168-180.

Donovan S.E., Eggleton P. \& Bignell D.E. 2001: Gut content analysis and new feeding group classification of termites. Ecol. Entomol. 26: 356-366.

EgGLeton P. \& TAYAsu I. 2001: Feeding groups, lifetypes and the global ecology of termites. - Ecol. Res. 16: 941-960.

Hirayama C., Konno K., Wasano N. \& Nakamura M. 2007: Differential effects of sugar-mimic alkaloids in mulberry latex on sugar metabolism and disaccharidases of Eri and domesticated silkworms: enzymatic adaptation of Bombyx mori to mulberry defense. - Insect Biochem. Mol. Biol. 37: 1348-1358.

Hongoh Y., Deevong P., Hattori S., Inoue T., Noda S., NoparatNARAPORN N., Kudo T. \& OhKuma M. 2006: Phylogenetic diversity, localization, and cell morphologies of members of the candidate phylum TG3 and a subphylum in the phylum Fibrobacteres, recently discovered bacterial groups dominant in termite guts. - Appl. Environ. Microbiol. 72: 6780-6788.

Hyodo F., Tayasu I., Inoue T., Azuma J., Kudo T. \& Abe T. 2003: Differential role of symbiotic fungi in lignin degradation and food provision for fungus-growing termites (Macrotermitinae: Isoptera). - Funct. Ecol. 17: 186-193.

Inward D.J.G., Vogler A.P. \& EgGleton P. 2007: A comprehensive phylogenetic analysis of termites (Isoptera) illuminates key aspects of their evolutionary biology. - Mol. Phylogenet. Evol. 44: 953-967.

JIN L.Q. \& ZHENG Y.G. 2009: Inhibitory effects of validamycin compounds on the termites trehalase. - Pestic. Biochem. Physiol. 95: 28-32.

Jorge J.A., Polizeli M.L., Thevelein J.M. \& Terenzi H.F. 1997: Trehalase and trehalose hydrolysis in fungi. - FEMS Microbiol. Lett. 154: 165-171.

Li Z.Q., Liu B.R., ZeNG W.H., XIAO W.L., Li Q.J. \& Zhong J.H. 2013: Character of cellulase activity in the guts of flagellatefree termites with different feeding habits. - J. Insect Sci. 13: $37,8 \mathrm{pp}$.

Lo N., Li B. \& Ujvari B. 2012: DNA methylation in the termite Coptotermes lacteus. - Insectes Soc. 59: 257-261.

Mitsumasu K., Azuma M., Nimimi T., Yamashita O. \& Yaginuma T. 2005: Membrane penetrating trehalase from silkworm Bombyx mori molecular cloning and localization in larval midgut. Insect Mol. Biol. 14: 501-508.

Ni J. \& ToKUdA G. 2013: Lignocellulose-degrading enzymes from termites and their symbiotic microbiota. - Biotech. $A d v$. 31: $838-850$.

NorRot C. 2001: The gut of termites (Isoptera). Comparative anatomy, systematics, phylogeny. II. Higher termites (Termitidae). - Ann. Soc. Entomol. Fr. 37: 431-471. 
OHKuma M. 2003: Termite symbiotic systems: efficient bio-recycling of lignocellulose. - Appl. Microbiol. Biotechnol. 61: $1-9$.

Osore H. \& OKeCH M.A. 1983: The partial purification and some properties of cellulase and $\beta$-glucosidase of Termitomyces conidiophores and fruiting bodies. - J. Appl. Biochem. 5: 127179.

Robinski G., Wrzeszcz A. \& Obuchowicz L. 1979: Differences in trehalase activity in the intestine of fed and starved larvae of Tenebrio molitor L. - Insect Biochem. 9: 485-488.

Shukla E., Thorat L.J., Nath B.B. \& Gaikwad S.M. 2014: Insect trehalase: Physiological significance and potential applications. - Glycobiology 25: 357-367.

Slaytor M. 2000: Energy metabolism in the termite and its gut microbiota. In Abe T., Bignell D.E. \& Higashi M. (eds): Termites: Evolution, Sociality, Symbioses, Ecology. Kluwer, Dordrecht, pp. 307-32.

Su N.Y. 2002: Novel technologies for subterranean termite control. - Sociobiology 40: 95-101.

Tatun N., Singtripop T., TungJitwitayakul J. \& Sakurai S. 2008 Regulation of soluble and membrane-bound trehalase activity and expression of the enzyme in the larval midgut of the bamboo borer Omphisa fuscidentalis. - Insect Biochem. Mol. Biol. 38: 788-795.

Tatun N., Vajarasathira B., Tungutitwitayakul J. \& Sakurai S. 2014a: Inhibitory effects of plant latex on trehalase activity and trehalase gene expression in the red flour beetle, Tribolium castaneum (Coleoptera: Tenebrionidae). — Eur. J. Entomol. 111: $11-18$.
Tatun N., Wangsantitham O., Tunguttwitayakul J. \& Sakurai S. 2014b: Trehalase activity in fungus-growing termite, Odontotermes feae (Isoptera: Termitideae) and inhibitory effect of validamycin. - J. Econ. Entomol. 107: 1224-1232.

Terra W.R., Ferreira C. \& BaKer J.E. 1996: Compartmentalization of digestion In Lehane M.J. \& Billingsley P.F. (eds): Biology of the Insect Midgut. Chapman \& Hall, London, pp. 206-235.

ToKuda G. \& Watanabe H. 2007: Hidden cellulase in termites: revision of an old hypothesis. - Biol. Lett. 3: 336-339.

Tokuda G., Lo N., Watanabe H., Arakawa G., Matsumoto T. \& NodA H. 2004: Major alteration of the expression site of endogenous cellulases in member of an apical termite lineage. - Mol. Ecol. 13: 3219-3228.

Tokuda G., Lo N. \& Watanabe H. 2005: Marked variations in patterns of cellulase activity against crystalline-vs carboxymethyl-cellulose in the digestive systems of diverse, wood-feeding termites. - Physiol. Entomol. 30: 372-380.

Wegener G., Tschiedel V., Schölder P. \& Ando O. 2003: The toxic and lethal effects of the trehalase inhibitor trehazolin in locust are caused by hypoglycemia. - J. Exp. Biol. 206: $1233-1240$.

YANG F., Xu B., Li J. \& HuAng Z. 2012: Transcriptome analysis of Termitomyces albuminosus reveals the biodegradation of lignocellulose. - Acta Microbiol. Sin. 52: 466-477.

Received August 31, 2017; revised and accepted November 2, 2017 Published online November 21, 2017 